\title{
Dampak disiplin kerja terhadap optimalisasi kinerja pegawai (Studi kasus pada Bagian Administrasi Pemerintah Umum Sekretariat Daerah Kota Pematangsiantar)
}

\author{
Robert Tua Siregar* ${ }^{*}$, Hery Pandapotan Silitonga² ${ }^{2}$ \& Ruth Tridianty \\ Sianipar ${ }^{2}$
}

\author{
1 Program Studi Manajemen, Sekolah Tinggi Ilmu Ekonomi Sultan Agung, Indonesia \\ 2Program Studi Akuntansi, Sekolah Tinggi Ilmu Ekonomi Sultan Agung, Indonesia
}

\begin{abstract}
Abstrak Penelitian ini bertujuan untuk mengetahui pengaruh disiplin kerja terhadap kinerja pegawai, dan apakah lingkungan kerja memoderasi pengaruh disiplin kerja terhadap kinerja pegawai. Variabel yang diteliti yaitu disiplin kerja, kinerja pegawai, dan lingkungan kerja. Metode penentuan sampel dengan cara sampel jenuh, maka semua populasi dijadikan sampel penelitian. Teknik analisis data menggunakan regresi sederhana, uji hipotesis, koefisien determinasi, dan moderated regression analysis. Hasil penelitian diperoleh disiplin kerja berpengaruh positif dan signifikan terhadap kinerja pegawai, dan lingkungan kerja mampu memoderasi pengaruh disiplin kerja terhadap kinerja pegawai. Penelitian ini menunjukkan bahwa dengan meningkatkan disiplin kerja akan meningkatkan kinerja pegawai, dan lingkungan kerja yang baik akan meningkatkan disiplin kerja pegawai.
\end{abstract}

Kata kunci: disiplin kerja; lingkungan kerja; kinerja pegawai; pegawai negeri sipil; moderated regression analysis

\begin{abstract}
This study aims to determine the effect of work discipline on employee performance, and whether the work environment moderates the effect of work discipline on employee performance. The variables studied were work discipline, employee performance, and work environment. The method of determining the sample by means of saturated samples, then all populations are used as research samples. Data analysis techniques using simple regression, hypothesis testing, coefficient of determination, and moderated regression analysis. The results showed that work discipline has a positive and significant effect on employee performance, and the work environment is able to moderate the effect of work discipline on employee performance. This research shows that by increasing work discipline will improve employee performance, and a good work environment will improve employee work discipline.
\end{abstract}

Keywords: work discipline; work environment; employee performance; government employee; moderated regression analysis

JEL Classification: J80o; J24; L25

\footnotetext{
* Penulis koresponden

E-mail: tuasirr@gmail.com

(C) 2020 Siregar dkk. Artikel ini dimiliki oleh penulis yang dilisensikan dibawah Creative Commons Attribution 4.0 International License. Lisensi ini memungkinkan penggunaan, pendistribusian, dan pencetakan kembali tanpa batas pada media apa pun, asalkan penulis dan sumber sebenarnya disebutkan
} 


\section{PENDAHULUAN}

Sumber daya manusia merupakan bagian yang terpenting dalam suatu organisasi, dan memiliki posisi yang strategis (Permatasari et al., 2019). Hal ini menunjukkan bahwa manusia memiliki peranan yang penting dalam mencapai tujuan dari organisasi, dimana manusia menjadi subjek untuk pelaksanaan setiap kebijakan serta kegiatan dalam organisasi. setiap sumber daya yang dimiliki suatu organisasi seperti modal, dan seluruh sarana dan prasarana tidak akan memberikan hasil yang optimal jika tidak mendapat dukungan dari sumber daya manusia (Widia \& Rusdianti, 2018). Kepercayaan akan pemerintah sebaiknya diimbangi dengan kinerja yang baik (Silitonga et al., 2018). Hal ini berarti jika tidak mendapat sumber daya manusia yang berkualitas, keberhasilan organisasi tidak akan bisa dicapai. Sumber daya manusia merupakan investasi yang sangat penting di dalam organisasi (Mangkunegara \& Waris, 2015). Hidup dan mati suatu organisasi tergantung dari peran manusia dalam organisasi sebagai karyawan (Priyono et al., 2016).

Aparatur Sipil Negara (ASN) dituntut untuk mempertanggungjawabkan kinerjanya yang dinilai berdasarkan prestasi dan penilaian kinerja (Undang-undang Nomor 5 Tahun 2014). Kinerja merupakan hasil dari suatu pekerjaan yang dicapai oleh seseorang dalam melaksanakan tugas yang diberikan kepadanya atas pengalaman, kepintaran, dan ketepatan waktu menyelesaikannya (Arianti \& Karmila, 2019). Dengan adanya kinerja maka tingkat pencapaian hasil akan terlihat sehingga akan diketahui seberapa jauh hasil dari tugas dan wewenang yang diberikan dapat dilaksanakan dengan maksimal.

Objek pada penelitian ini pada Bagian Administrasi Pemerintahan Umum Sekretariat Daerah Kota Pematangsiantar merupakan sebuah organisasi perangkat daerah yang berupaya memberikan pelayanan prima guna terwujudnya dengan baik pelaksanaan tugas penyelenggaraan pemerintah, administrasi pemerintahan serta terpenuhinya pelayanan administratif kepada seluruh perangkat daerah dengan mengimplementasikan cara kerja yang cepat, efisien dan transparan terhadap kebutuhan perangkat daerah. Berikut pada Tabel 1 dipaparkan fenomena kinerja pegawai berdasarkan Peraturan Pemerintah Republik Indonesia Nomor 46 tentang Penilaian Prestasi Kerja Pegawai Negeri Sipil.

Tabel 1. Fenomena Kinerja Pegawai

\begin{tabular}{lcccccc}
\hline Aspek Kinerja Pegawai & SB & B & CB & TB & STB & Jumlah \\
\hline Sasaran Kinerja Pegawai (SKP) & $25 \%$ & $50 \%$ & $15 \%$ & $10 \%$ & $0 \%$ & $100 \%$ \\
Perilaku Kerja (PK) & $15 \%$ & $50 \%$ & $25 \%$ & $10 \%$ & $0 \%$ & $100 \%$ \\
Rata-rata & $20 \%$ & $50 \%$ & $20 \%$ & $10 \%$ & $0 \%$ & $100 \%$ \\
\hline
\end{tabular}

Sumber: Data Diolah Penulis (2020)

Dari uraian pada Tabel 1 dapat diketahui bahwa kinerja pegawai pada Bagian Administrasi Pemerintahan Umum Sekretariat Daerah Kota Pematangsiantar masih kurang optimal. Hal ini dapat dilihat pada dimensi sasaran kerja pegawai yang di kategori tidak baik sebesar $10 \%$ pada indikator waktu, hal ini disebabkan karena masih adanya pegawai yang belum mampu memaksimalkan waktu kerja sesuai jam 
kerja, dan masih ada pegawai yang kurang disiplin dalam penggunaan waktu jam istirahat dan tidak semua pegawai yang mengikuti kegiatan upacara pagi dan briefing sore setiap hari.

Disiplin kerja merupakan salah satu faktor yang harus diperhatikan oleh suatu organisasi dalam meningkatkan kinerja atau produktivitas organisasi (Arianti \& Karmila, 2019). Dalam setiap organisasi, terdapat banyak pegawai yang melaksanakan tugasnya tidak sesuai dengan yang diharapkan, mereka banyak melakukan kesalahan yang mengakibatkan pekerjaan tersebut tidak dapat selesai tepat waktu (Hendrawardani \& Sukamto, 2019). Disiplin kerja menjadi alat bagi manajerial dalam melakukan komunikasi kepada pegawai untuk merubah perilakunya. Disiplin kerja yang tidak optimal akan mempersulit dalam melakukan pelayanan dan mengakibatkan kerugian bagi yang dilayani. Mengoptimalkan disiplin kerja akan meningkatkan kinerja pegawai, dengan meningkatkan kinerja pegawai dalam organisasi maka akan mencapai tujuan dan mempertahankan kelangsungan hidup dari organisasi hal ini sejalan dengan penelitian yang dilakukan (Nugrahaningsih \& Julaela, 2017; Widia \& Rusdianti, 2018; Mangkunegara \& Waris, 2015).

Lingkungan kerja menjadi aspek dan gejala fisik yang mempengaruhi individu dalam organisasi. Lingkungan kerja merupakan segala yang ada di sekitar pekerjaan dilakukan yang dapat mempengaruhi pegawai dalam organisasi dalam melaksanakan pekerjaan yang dibebankan kepadanya (Nugrahaningsih \& Julaela, 2017). Lingkungan kerja fisik antara lain kelayakan peralatan kerja seperti peralatan kerja komputer dan printer yang sudah tidak layak digunakan tapi masih dipakai pegawai dalam melaksanakan kegiatannya dan lingkungan non fisik diantaranya hubungan kerja antara pegawai, atasan dengan bawahan menunjukkan masih kurang harmonis seperti pada saat atasan berada di ruangan terjadi suasana yang kaku antara pegawai dengan atasan dalam bekerja (Suwondo \& Sutanto, 2015). Dengan terlaksananya beban pekerjaan yang dibebankan kepada pegawai akan meningkatkan kinerjanya, hal ini sejalan dengan penelitian yang dilakukan Nugrahaningsih dan Julaela (2017).

\section{Kinerja Pegawai}

Kinerja merupakan hasil kerja yang dicapai seseorang karyawan dalam melaksanakan tugas yang dibebankan kepadanya atas dasar kecakapan, pengalaman dan ketepatan waktu dalam hal kemampuan bekerja secara efektif dan efisien (Handoko, 2012). Perusahaan pada era perkembangan kompetitif saat ini membutuhkan karyawan yang berprestasi tinggi (Pawirosumarto et al., 2017). Dengan melakukan penilaian kinerja pegawai akan meningkatkan produktivitas dan mencapai kinerja yang diharapkan.

Dalam mengukur kinerja pegawai, dimensi kinerja terdiri dari hasil, kualitas dari hasil, ketepatan waktu dari hasil, kehadiran, kemampuan bekerjasama, biaya pelayanan, kualitas dan standar, cakupan pelayanan, serta kepuasan. Penilaian kinerja merupakan suatu sistem formal yang dapat menilai serta mengevaluasi kinerja individu maupun tim (Mondy, 2008). Pengukuran kinerja dilakukan untuk 
mengetahui apakah pegawai dapat menyelesaikan kewajiban sesuai dengan batas waktu yang diberikan (Suwondo \& Sutanto, 2015). Penilaian kinerja dilakukan untuk meminimalkan sikap yang tidak seharusnya dan pencapaian akan tugas yang dibebankan kepadanya dilakukan melalui penghargaan maupun hukuman. Lepas dari penekanan tersebut, sistem penilaian kinerja karyawan yang efektif akan mengevaluasi prestasi dan menginspirasi rencana-rencana untuk pengembangan, tujuan, dan sasaran.

\section{Disiplin}

Di dalam organisasi disiplin sangat lah penting, terutama disiplin yang diterapkan kepada para pegawai di dalam organisasi tersebut. Disiplin merupakan bentuk kepatuhan kepada peraturan baik tertulis maupun tidak tertulis (Pawirosumarto et al., 2017). Disiplin menjadi penggerak untuk setiap pegawai, agar pekerjaan dapat berjalan dengan lancar (Permatasari et al., 2019). Pegawai yang disiplin akan menaati tata tertib, dan norma-norma yang berlaku dalam organisasi. bila setiap pegawai memiliki disiplin yang baik akan mempercepat pencapaian tujuan organisasi, sedangkan bila disiplin kurang optimal akan menjadi penghalang dan memperlambat pencapaian tujuan organisasi (Widia \& Rusdianti, 2018).

Disiplin digunakan untuk mengatur setiap anggota dalam organisasi mengenai sikap dan tindakan agar melancarkan pencapaian dari tujuan organisasi. Dimensi disiplin kerja mengenai kewajiban dan larangan dibuat untuk mengukur tingkat ketaatan pada peraturan kerja yang ada di dalam organisasi. Dimensi disiplin kerja adalah agar karyawan dapat memenuhi serta menaati segala peraturan yang ada di perusahaan untuk kepentingan karyawan tersebut maupun kepentingan perusahaan dalam mencapai tujuan perusahaan. Dengan meningkatkan akan kesadaran dalam mengimplementasikan aturan yang terdapat dalam organisasi diwujudkan dalam disiplin kerja yang tinggi yang akan meningkatkan kinerja dari pegawai (Priyono et al., 2016).

\section{Lingkungan Kerja}

Lingkungan kerja sangat mempengaruhi kinerja setiap bagian dari organisasi. Lingkungan fisik seperti fasilitas-fasilitas yang membantu pegawai dalam melaksanakan tugas yang diberikan (Yeh \& Huan, 2017). Lingkungan kerja berhubungan dengan tingkat kenyamanan, efisiensi, dan keamanan demi memuaskan kebutuhan fisik dan pegawai di tempat kerja (Nugrahaningsih \& Julaela, 2017). Lingkungan kerja terbagi atas lingkungan kerja fisik dan non fisik dimana lingkungan fisik meliputi segala sesuatu yang ada di tempat kerja yang berbentuk fisik dan lingkungan non fisik meliputi suasana kerja atau hubungan antara atasan, bawahan, serta rekan kerja (Mangkunegara \& Prabu, 2017).

Sangat perlu bagi suatu instansi untuk memperhatikan faktor-faktor yang mempengaruhi lingkungan kerja, karena dengan adanya faktor lingkungan kerja yang baik akan mendukung hasil dari kinerja yang dilakukan setiap pegawai dalam organisasi. Faktor-faktor yang mempengaruhi lingkungan untuk membantu setiap pegawai dalam organisasi dapat memaksimalkan kinerjanya, seperti faktor 
keamanan, ruang gerak, faktor cahaya, kebisingan, tata warna, musik, dan sirkulasi udara di dalam lingkungan kerja tersebut.

Penelitian ini mengenai sumber daya manusia dalam organisasi pemerintah. Rumusan masalah dalam penelitian ini bagaimana pengaruh disiplin terhadap kinerja pegawai, dan apakah lingkungan kerja dapat memoderasi hubungan disiplin terhadap kinerja pegawai. Tujuan dari penelitian ini untuk mengetahui pengaruh disiplin terhadap kinerja pegawai, dan mengetahui apakah lingkungan kerja dapat memoderasi hubungan disiplin terhadap kinerja pegawai. Berikut metode yang digunakan untuk mencapai tujuan dalam penelitian ini.

\section{METODE PENELITIAN}

\section{Kerangka Penelitian}

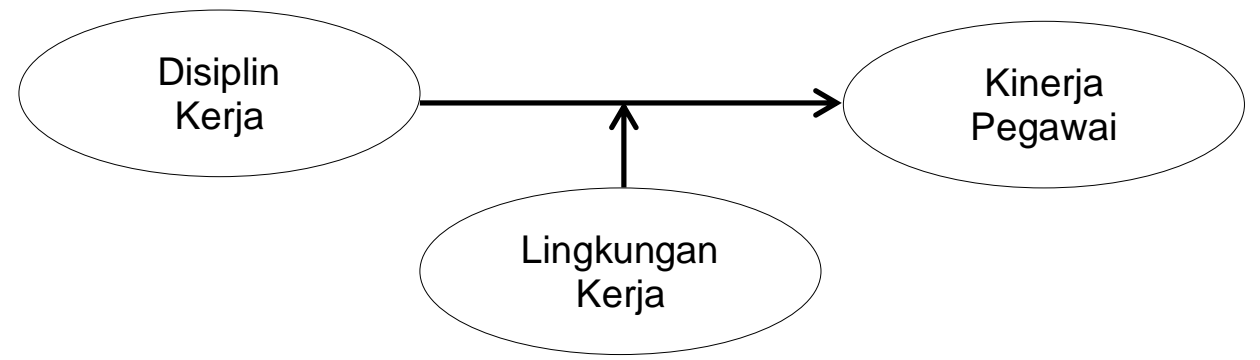

Gambar 1. Kerangka Pemikiran

Kerangka pemikiran dalam penelitian ini diilustrasikan seperti pada Gambar 1. Kerangka pemikiran tersebut disusun untuk mencapai tujuan penelitian. Hal ini untuk menguji hipotesis sebagai berikut:

$\mathrm{H}_{1}$ : Disiplin kerja berpengaruh terhadap kinerja pegawai

$\mathrm{H}_{2}$ : Lingkungan kerja memoderasi pengaruh disiplin kerja terhadap kinerja pegawai.

\section{Desain Penelitian}

Desain penelitian yang digunakan dengan menggunakan penelitian kepustakaan dengan mencari infromasi menggunakan alat elektronik dan bukubuku, dan penelitian lapangan melakukan dengan cara mengumpulkan data melalui observasi lapangan (Imam, 2013). Objek penelitian dalam hal ini adalah pegawai pada Administrasi Pemerintahan Umum Kota Pematangsiantar.

\section{Pengumpulan Data}

Populasi pada penelitian ini ialah seluruh Pegawai Negeri Sipil (PNS) pada Administrasi Pemerintahan Umum Sekretariat Daerah Kota Pematangsiantar yang berjumlah 28 orang. Sampel dalam penelitian ini menggunakan sampel jenuh, yang dimana seluruh populasi digunakan sebagai sampel penelitian. Teknik pengumpulan data menggunakan metode kuesioner, metode wawancara, dan dokumentasi. Sebelum melakukan pengumpulan data dengan kuesioner dilakukan 
uji instrumen data, dengan uji validitas, dan reliabilitas. Tabel 2 menunjukkan bahwa semua indikator variabel dalam penelitian ini adalah valid.

Tabel 2. Hasil Uji Validitas

\begin{tabular}{llccc}
\hline \multicolumn{2}{c}{ Variabel } & rhitung & rkritis & Hasil Uji \\
\hline Lingkungan Kerja (X) & Fisik & 0,545 & 0,3 & Valid \\
& Non Fisik & 0,474 & 0,3 & Valid \\
Kinerja Pegawai (Y) & Sasaran Kerja Pegawai & 0,450 & 0,3 & Valid \\
& Perilaku Kerja & 0,551 & 0,3 & Valid \\
Disiplin Kerja (Z) & Kewajiban & 0,474 & 0,3 & Valid \\
& Menjauhi Larangan & 0,477 & 0,3 & Valid \\
\hline
\end{tabular}

Sumber: Data Diolah (2020)

Kemudian, hasil uji reliabilitas pada Tabel 3 dapat disimpulkan bahwa indikator variabel dalam penelitian ini reliabel.

Tabel 3. Hasil Uji Reliabilitas

\begin{tabular}{ccc}
\hline Cronbach's Alpha & Nof item & Hasil Uji \\
\hline 0,953 & 10 & Reliabel \\
0,952 & 20 & Reliabel \\
0,953 & 32 & Reliabel
\end{tabular}

Sumber: Data Diolah (2020)

\section{Teknik Analisis Data}

Teknik analisis data yang digunakan dalam penelitian ini menggunakan uji asumsi klasik, analisis regresi sederhana, uji hipotesis, koefisien determinasi, dan Moderated Regression Analysis (MRA).

\section{HASIL DAN PEMBAHASAN}

\section{Uji Asumsi Klasik}

Hasil uji normalitas menggunakan uji Kolmogorov-Smirnov dapat dilihat pada Tabel 4. Berdasarkan Tabel 4, Asymp. Sig (2-tiled) pada total X (disiplin) sebesar 0,718 , total $Y$ (kinerja pegawai) sebesar 0,614 , total $Z$ (lingkungan kerja) sebesar 0,733, serta total keseluruhan 0,971, seluruh Asymp. Sig (2-tailed) >0,05. Maka dapat disimpulkan seluruh variabel berdistribusi normal.

\section{Uji Regresi Sederhana}

Hasil uji regresi linaer sederhana, dapat dilihat pada Tabel 5. Diperoleh model persamaan $Y=25,692+0,428$ Disiplin, artinya terdapat pengaruh positif antara disiplin kerja terhadap kinerja pegawai pada Bagian Administrasi Pemerintahan Umum Sekretariat Daerah Kota Pematangsiantar. Nilai konstanta sebesar 25,692 dengan arah hubungan positif menunjukkan apabila variabel disiplin dianggap konstan maka kinerja pegawai sudah terbentuk sebesar 25,692. Nilai disiplin sebesar 0,428 dengan arah positif menunjukkan apabila disiplin kerja ditingkatkan satu satuan makan kinerja pegawai akan meningkat sebesar 0,428. 
Tabel 4. Uji Kolmogorov-Smirnov

\begin{tabular}{|c|c|c|c|c|c|}
\hline & & $\begin{array}{l}\text { Disiplin } \\
\text { Kerja }\end{array}$ & $\begin{array}{c}\text { Kinerja } \\
\text { Pegawai }\end{array}$ & $\begin{array}{c}\text { Lingku- } \\
\text { ngan Kerja }\end{array}$ & $\begin{array}{c}\text { Unstandardized } \\
\text { Residual }\end{array}$ \\
\hline $\mathrm{N}$ & & 28 & 28 & 28 & 28 \\
\hline Normal & Mean & 114,3214 & 74,6071 & 38,3571 & ,0000000 \\
\hline Parameters ${ }^{a, b}$ & $\begin{array}{l}\text { Std. } \\
\text { Deviation }\end{array}$ & 11,52149 & 6,70179 & 4,37344 & 4,03266112 \\
\hline Most Extreme & Absolute &, 131 & ,143 & ,130 & ,092 \\
\hline \multirow[t]{2}{*}{ Differences } & Positive & ,072 & ,143 & ,098 & ,092 \\
\hline & Negative &,- 131 &,- 062 &,- 130 &,- 078 \\
\hline \multicolumn{2}{|c|}{ Kolmogorov-Smirnov Z } & ,696 & ,758 & ,687 & ,488 \\
\hline \multicolumn{2}{|c|}{$\begin{array}{l}\text { Asymp. Sig. (2-tailed) } \\
\text { a. Test distribution is Normal. } \\
\text { b. Calculated from data. }\end{array}$} & ,718 &, 614 & ,733 & ,971 \\
\hline
\end{tabular}

Sumber: Data Diolah (2020)

Tabel $5 . \quad$ Hasil SPSS

\begin{tabular}{lcccc}
\hline \multirow{2}{*}{ Model } & \multicolumn{2}{c}{ Unstandardized Coefficients } & \multicolumn{2}{c}{ Standardized Coefficients } \\
& B & Std. Error & Beta \\
\hline 1 & (Constant) & 25,692 & 8,878 &, 736 \\
& Disiplin Kerja &, 428 &, 077 &
\end{tabular}

Sumber: Data Diolah (2020)

\section{Uji Hipotesis (Uji t)}

Hasil uji t dapat dilihat pada Tabel 6. Uji t memperlihatkan thitung sebesar 5,537, dan $t_{\text {tabel }}$ sebesar 2,059, dengan taraf signifikansi $0,000<0,05$, artinya disiplin kerja berpengaruh signifikan terhadap kinerja pegawai. Yang artinya jika disiplin ditingkatkan maka kinerja pegawai akan meningkat.

Tabel 6. Hasil SPSS

\begin{tabular}{llll}
\hline \multicolumn{2}{l}{ Model } & $\mathrm{t}$ & Sig. \\
\hline $1 \quad$ (Constant) & 2,894 &, 008 \\
& Disiplin Kerja & 5,537 &, 000 \\
a. Dependent Variable: Kinerja Pegawai & & \\
\hline
\end{tabular}

Sumber: Data Diolah (2020)

\section{Koefesien Determinasi}

Berdasarkan Tabel 7 diperoleh nilai koefisien determinasi $\mathrm{R}$ Square sebesar 0,541 , atau $54,1 \%$, hal ini berarti tinggi rendahnya kinerja pegawai dapat dijelaskan sebesar $54,1 \%$ oleh disiplin, sedangkan sisa nya $45,9 \%$ dijelaskan oleh faktor lain yang tidak diteliti dalam penelitian ini.

Tabel 7. Koefisien Determinasi

\begin{tabular}{rrrrr}
\hline Model & $\mathrm{R}$ & $\mathrm{R}$ Square & Adjusted R Square & Std. Error of the Estimate \\
\hline, $736^{\mathrm{a}}$ &, 541 &, 523 & 4,62652 \\
\hline
\end{tabular}

a. Predictors: (Constant), Disiplin Kerja

b. Dependent Variable: Kinerja Pegawai

Sumber: Data Diolah (2020) 


\section{Moderated Regression Analysis (MRA)}

Hasil uji MRA menunjukkan thitung sebesar 2,700 dengan nilai Sig sebesar 0,012 $<0,05$, atau thitung $>t_{\text {tabel, }}$ artinya lingkungan kerja memoderasi pengaruh disiplin terhadap kinerja pegawai. Selengkapnya hasil uji MRA dapat dilihat pada Tabel 8.

Tabel 8. Moderated Regression Analysis

\begin{tabular}{|c|c|c|c|c|c|c|}
\hline \multirow[t]{2}{*}{ Model } & & \multicolumn{2}{|c|}{$\begin{array}{l}\text { Unstandardized } \\
\text { Coefficients }\end{array}$} & \multirow{2}{*}{$\begin{array}{c}\text { Standardized } \\
\text { Coefficients } \\
\text { Beta }\end{array}$} & \multirow[t]{2}{*}{$\mathrm{t}$} & \multirow[t]{2}{*}{ Sig. } \\
\hline & & $\mathrm{B}$ & Std. Error & & & \\
\hline & (Constant) & 41,918 & 9,979 & & 4,201 & ,000 \\
\hline 1 & $\begin{array}{l}\text { Disiplin } \\
\text { Disiplin Kerja*Lingkungan } \\
\text { Kerja }\end{array}$ & $\begin{array}{l}, 074 \\
, 005\end{array}$ & $\begin{array}{l}148 \\
, 002\end{array}$ & $\begin{array}{l}\text {, 126 } \\
\text {,689 }\end{array}$ & $\begin{array}{r}, 496 \\
2,700\end{array}$ & $\begin{array}{l}, 625 \\
, 012\end{array}$ \\
\hline
\end{tabular}

Sumber: Data Diolah (2020)

Dari hasil tanggapan responden mengenai disiplin diperoleh kriteria jawaban baik. Para pegawai menganggap disiplin merupakan hal penting dalam meningkatkan kinerja pegawai. Dengan meningkatkan disiplin kerja para anggota organisasi hal ini dapat meningkatkan kinerjanya. Hal ini sejalan dengan penelitian yang dilakukan Nugrahaningsih dan Julaela (2017), Widia dan Rusdianti (2018), dan Mangkunegara dan Waris (2015). Lingkungan kerja mendapat tanggap responden dengan kriteria jawaban baik. Dengan memiliki lingkungan kerja yang baik, maka akan meningkatkan disiplin para anggota organisasi yang akan meningkatkan kinerja pegawai. Dengan adanya lingkungan kerja yang baik akan memperkuat pengaruh disiplin kerja terhadap kinerja pegawai. Dari tanggap responden mengenai kinerja pegawai mendapatkan kriteria jawaban baik. Hal ini berarti kinerja merupakan hal yang sangat diperhatikan oleh para anggota organisasi. Peningkatan kualitas hidup juga menjadi perhatian utama dengan meningkatkan pendapatan (Siregar, 2016). Walaupun demikian pegawai harus lebih meningkatkan kinerjanya dalam bekerja guna mencapai tujuan instansi dengan efektif dan efisien.

\section{KESIMPULAN}

Berdasarkan hasil penelitian diperoleh kesimpulan disiplin kerja berpengaruh terhadap kinerja pegawai. Dengan meningkatkan disiplin kerja yang dimiliki oleh pegawai akan meningkatkan kinerjanya. Untuk meningkatkan disiplin kerja perlu diberikan penghargaan dan hukuman. Lingkungan kerja mampu memoderasi pengaruh disiplin kerja terhadap kinerja pegawai. Dengan lingkungan kerja yang baik secara fisik maupun non-fisik akan meningkatkan disiplin kerja para pegawai dan meningkatkan kinerja pegawai. Dalam meningkatkan lingkungan kerja sebaiknya mengganti peralatan yang tidak layak pakai agar lebih mendukung pegawai dalam meningkatkan pekerjaannya.

Pada penelitian selanjutnya, diharapkan menambahkan variabel yang diteliti seperti prestasi kerja, loyalitas, kepercayaan, pengembangan karir, kemampuan intelektual, gaya kepemimpinan, pelatihan, kepuasan kerja pendidikan, etos kerja, budaya organisasi variabel lain yang tidak diteliti dalam penelitian ini. 


\section{DAFTAR PUSTAKA}

(1) Arianti, N. D., \& Karmila, D. (2019). Pengaruh Gaya Kepemimpinan, Motivasi dan Disiplin Kerja Kepala Kantor terhadap Kinerja Pegawai Kesyahbandaran Otoritas Pelabuhan Kelas II Tanjung Balai Karimun. Agustus Jurnal Maritim, 1(1), 4-10. http://www.ejurnal.universitaskarimun.ac.id/index.php/OJSM/article/view/1

(2) Suwondo, D. I., \& Sutanto, E. M. (2015). Hubungan Lingkungan Kerja, Disiplin Kerja, dan Kinerja Karyawan. Jurnal Manajemen dan Kewirausahaan (Journal of Management and Entrepreneurship), 17(2), 135-144. https://doi.org/10.9744/jmk.17.2.145-154 https://doi.org/10.9744//jmk.17.2.135

(3) Handoko, H. T. (2012). Manajemen Sumber Daya Manusia. BPFE.

(4) Hendrawardani, B., \& Sukamto, J. (n.d.2019). Pengaruh Disiplin Kerja terhadap Kinerja Pegawai pada PT Wom Finance Kebumen. Jurnal E-Bis (Ekonomi-Bisnis), 3(1), 1-15. https://doi.org/10.37339/e-bis.v3i1.111

(5) Imam, G. (2013). Aplikasi analisis multivariate dengan Program SPSS. Universitas Diponogoro.

(6) Mangkunegara, A. A., \& Prabu, A. (2017). Manajemen Sumber Daya Manusia Perusahaan. Remaja Rosdakarya.

(7) Mangkunegara, A. P., \& Waris, A. P. M. dan A. (2015). Effect of Training, Competence and Discipline on Employee Performance in Company (Case Study in PT. Asuransi Bangun Askrida). Procedia - Social and Behavioral Sciences, 211, 1240-1251. https://doi.org/10.1016/j.sbspro.2015.11.165

(8) Mondy., Wayne RR. W. (2008). Manajemen Sumber Daya Manusia. Erlangga.

(9) Nugrahaningsih, H., \& Julaela. (2017). Pengaruh Disiplin Kerja dan Lingkungan Kerja Terhadap Kinerja Karyawan dengan Kepuasan Kerja Sebagai Variabel Intervening pada PT. Tempuran Mas. Media Manajemen JasaJurnal Online Internasional \& Nasional, 4(1), 61-76. http://journal.uta45jakarta.ac.id/index.php/MMJ/article/view/712

(10) Pawirosumarto, S., Sarjana, P. K., \& Muchtar, M. (2017). Factors affecting employee performance of PT.Kiyokuni Indonesia. International Journal of Law and Management, 59(4), 602-614. https://doi.org/10.1108/IJLMA-03-2016-0031

(11) Permatasari, D., Sufian, S., \& Rachmansyah, Y. (2019). Analisis Pengaruh Motivasi Kerja, Kompetensi dan Beban Kerja terhadap Kinerja Pegawai dengan Disiplin Kerja Sebagai Variabel Moderasi (Studi Empiris pada Pengurus Barang di Lingkungan Pemerintah Kota Semarang). Magisma: Jurnal IImiah Ekonomi dan Bisnis, 7(1), 19-34. https://doi.org/10.35829/magisma.v7i1.37

(12) Priyono, Marzuki, \& Soesatyo, Y dkk. (2016). Influence of motivation and discipline on the performance of employees (Studies on, CV Eastern Star Home in Surabaya)Influnce of Mativation and Dicipline on the Performance of Employees (Studies on, CV Eastern Star Home in). Journal of Global Economics, Management and Business Research, 5(3) 212-220.

https://www.ikprress.org/index.php/JGEMBR/article/view/2093

(13) Silitonga, H.P., Astuty, W., \& Irfan. (2018). Pengaruh Partisipasi Anggaran dan Akuntansi Pertanggungjawaban Terhadap Kinerja Manajerial dengan Pengendalian Diri (Locus Of Control) Sebagai Variabel Moderasi (Studi Kasus Pada Organisasi Perangkat Daerah (OPD) Kota Pematangsiantar). Sekolah Tinggi Ilmu Ekonomi Sultan Agung.

(14) Siregar, R.T. (2016). The Influence of Tourism Sector to the Income of Simalungun Regency Area. IOSR Journal of Economics and Finance (IOSR-JEF), 7(6), 6-11. https://doi.org/10.9790/5933-0706040611 
(15) Widia, A., \& Rusdianti, E. (2018). Pengaruh Displin Kerja Dan Kepuasan Kerja Terhadap Kinerja Pegawai Dengan Tambahan Penghasilan Pegawai Sebagai Variabel Moderating. Jurnal Riset Ekonomi dan Bisnis, 11(3), 191. https://doi.org/10.26623/jreb.v11i3.1143

(16) Yeh, S.S., \& Huan, T.C. (2017). Assessing the impact of work environment factors on employee creative performance of fine-dining restaurants. Tourism Management, 58, 119-131. https://doi.org/10.1016/j.tourman.2016.10.006 